\title{
Hinge Fracture during Cervical Open-door Laminoplasty: Does it Affect Clinical and Radiographic Outcomes?
}

\author{
Sung Hoon Cho, Jung Hwan Lee, Chung Kee Chough, Won II Joo, \\ Hae Kwan Park, Kyung Jin Lee, Hyoung Kyun Rha \\ Catholic Neuroscience Center, Department of Neurosurgery, Yeouido St. Mary's Hospital, \\ The Catholic University College of Medicine, Seoul, Korea
}

\begin{abstract}
Objective: The purpose of this study was to determine whether the status of the hinge gutter affected clinical and radiographic outcomes of cervical open door laminoplasty.

Methods: We retrospectively analyzed 43 patients who had undergone cervical open door laminoplasty. 23 CT scans were performed at 2 days post-operation. The number of CT scans at 3, 6, 12 and 24 months were 16, 12, 21 and 11, respectively. We collected perioperative and follow-up data, including clinical and radiographic results.

Results: There were 7 patients without a hinge fracture and 16 patients with one or more hinge fractures at 2 days postoperation. There were 90 hinges, and the rate of ideal greenstick deformation of the hinge was $63 \%$ on 2-day-postoperative CT scans. Postoperative VAS scores of neck pain $(\mathrm{p}=0.012)$ in patients without a hinge fracture were higher than in patients with hinge fractures. The hinge healing rates were $37 \%$ at 3 months, $57.4 \%$ at 6 months, $86.4 \%$ at 12 months, and $85.4 \%$ at 24 months. Among the patients, 14 patients had healed hinges, and 7 patients had one or more hinge(s) that was/were not healed at 12 months post-operation. However, in clinical and radiographic outcomes, there was no difference between these patients.

Conclusion: Cervical open door laminoplasty was safe and provided stable reconstruction of laminar expansion. In radiographs, the difference between hinges that had healed and hinges that had not healed was statistically negligible. Hinge fractures might not influence the clinical and radiographic outcomes of cervical open door laminoplasty.
\end{abstract}

Key Words: Cervical vertebrae $\cdot$ Treatment outcome $\cdot$ Laminoplasty $\cdot$ Fracture

\section{INTRODUCTION}

Cervical open-door laminoplasty is a suitable treatment option for patients with cervical compressive myelopathy ${ }^{7,8)}$. Although several techniques have been introduced, the basic procedure of this operation is to open one side of the lamina and make a greenstick deformation on the opposite lamina ${ }^{5,6}$. These deformed laminae are called hinges. Regardless of the degree of caution undertaken while performing surgery, hinge frac-

- Received: April 4, 2014 - Revised: May 19, 2014

- Accepted: May 28, 2014

Corresponding Author: Jung Hwan Lee, MD

Catholic Neuroscience Center, Department of Neurosurgery, Yeouido

St. Mary's Hospital, The Catholic University of Korea College of Medicine,

62 Yeouido-dong, Yeongdeungpo-gu, Seoul 150-713, Korea

Tel: +82-2-3779-1187, Fax: +82-2-786-5809

E-mail: juwan@pusan.ac.kr

@This is an Open Access article distributed under the terms of the Creative

Commons Attribution Non-Commercial License (http://creativecommons.org/ licenses/by-nc/3.0/) which permits unrestricted non-commercial use, distribution, and reproduction in any medium, provided the original work is properly cited. tures $(\mathrm{HFs})$ sometimes occur. Moreover, a delayed fracture can occur because of a mechanical weakness in the deformed lamina, even if an ideal greenstick deformation was made. Fortunately, many papers have reported that the hinges heal, in most cases, without serious complications ${ }^{1,6,9)}$. However, there is little information regarding the overall status of the hinge and its clinical and radiographic implications. The purpose of this study was to determine the correlation between fractured and not fractured hinges using clinical and radiographic measurements.

\section{MATERIALS AND METHODS}

\section{Patient's Data}

From January 2004 to December 2012, 75 patients with cervical compressive myelopathy were treated with open-door laminoplasty. Among them, 43 patients had one or more available postoperative computed tomography (CT) scans. There were 28 men and 15 women. The mean age at the time of the surgery was 62.1 (range, 43-80 years). There were 21 patients 
Table 1. Patient demographics

\begin{tabular}{ll}
\hline \hline Parameters & Number \\
\hline Total patients & 43 \\
Age (years) & $62.1(43-80)$ \\
Sex (male/female) & $28 / 15$ \\
OPLL/CSM & $21 / 22$ \\
Laminoplasty range & \\
C3-C5 & 5 \\
C3-C6 & 26 \\
C3-C7 & 2 \\
C4-C6 & 8 \\
C4-C7 & 2 \\
CT scans obtained & 83 (total) \\
2 days & 23 \\
3 months & 16 \\
6 months & 12 \\
12 months & 21 \\
24 months & 11 \\
\hline
\end{tabular}

OPLL, ossification of posterior longitudinal ligament; CSM, cervical spondylotic myelopathy; CT, computed tomography.

with symptomatic ossification of the posterior longitudinal ligaments, and the other patients were diagnosed with spondylotic myelopathy. Table 1 summarizes the demographics of the enrolled patients.

\section{Surgical Procedure}

A standard posterior approach of the cervical spine was used for the open door laminoplasty. The number of laminoplasty segments depended on the extent of spinal cord compression. At first, the junction of the lateral mass and lamina was drilled into with a 3-mm match head burr, and a linear laminectomy was made. The ligament flavum was split with a Kerrison rongeur. Next, on the opposite side, the dorsal cortex was removed and the ventral cortex was thinned until a greenstick deformation of the hinge was attained. The laminae were elevated and the open side was stabilized with plates and screws (Centerpiece, Medtronic Sofamor Daneck, Memphis, Tennessee; Arch, Synthes, Paoli, Penssylvania). Bone grafting was not performed on the hinge. Postoperatively, the patients were encouraged to move their necks without a brace unless they felt severe neck pain.

\section{Clinical Measurement}

For clinical assessment, visual analog scale (VAS) scores of neck pain (VASn), VAS scores of arm pain (VASa), and neck disability index (NDI) scores were obtained during the pre-
Table 2. Evaluation of cenvical myelopathy using the scoring system proposed by the Japanese Orthopaedic Association (JOA) score*

\begin{tabular}{|c|c|}
\hline Function & Grade \\
\hline \multicolumn{2}{|l|}{ Motor function } \\
\hline \multicolumn{2}{|l|}{ Upper extremity } \\
\hline Impossible to eat with chopsticks or spoon & 0 \\
\hline Possible to eat with a spoon but not chopsticks & 1 \\
\hline Possible to eat with chopsticks, but inadequate & 2 \\
\hline Possible to eat with chopsticks, awkward & 3 \\
\hline \multicolumn{2}{|l|}{ Lower extremity } \\
\hline Impossible to walk & 0 \\
\hline Needs a cane or aid on flat ground & 1 \\
\hline Needs a cane or aid only on stairs & 2 \\
\hline Possible to walk without a cane or aid but slowly & 3 \\
\hline Normal & 4 \\
\hline \multicolumn{2}{|l|}{ Sensory function } \\
\hline \multicolumn{2}{|l|}{ Upper extremity } \\
\hline Apparent sensory loss & 0 \\
\hline Minimal sensory loss & 1 \\
\hline Normal & 2 \\
\hline \multicolumn{2}{|l|}{ Lower extremity } \\
\hline Apparent sensory loss & 0 \\
\hline Minimal sensory loss & 1 \\
\hline Normal & 2 \\
\hline \multicolumn{2}{|l|}{ Trunk } \\
\hline Apparent sensory loss & 0 \\
\hline Minimal sensory loss & 1 \\
\hline Normal & 2 \\
\hline \multicolumn{2}{|l|}{ Bladder function } \\
\hline Complete retention & 0 \\
\hline $\begin{array}{l}\text { Severe disturbance (sense of retention, dribbling, } \\
\text { incomplete continence) }\end{array}$ & 1 \\
\hline Mild disturbance (urinary frequency, urinary hesitancy) & 2 \\
\hline Normal & 3 \\
\hline
\end{tabular}

${ }^{*}$ A cumulative normal grade in a healthy individual is 17

operative and postoperative periods ${ }^{10)}$. The severity of the myelopathy was evaluated by the Japanese Orthopaedic Association (JOA) cervical myelopathy score (Table 2). The recovery rate (RR) of the JOA score [(postoperative JOA score - preoperative JOA score) $] /(17$-preoperative JOA score $) \times 100 \%$ ] was evaluated using a formula suggested by Hirabayashi, et al. ${ }^{2)}$. The achieved JOA score (postoperative JOA score - preoperative JOA score) was also evaluated. Postoperative outcomes were evaluated 12 months after the surgery.

\section{Radiographic Measurement}

Pre- and postoperative lateral radiographs including neutral, maximum flexion, and extension views of the cervical 

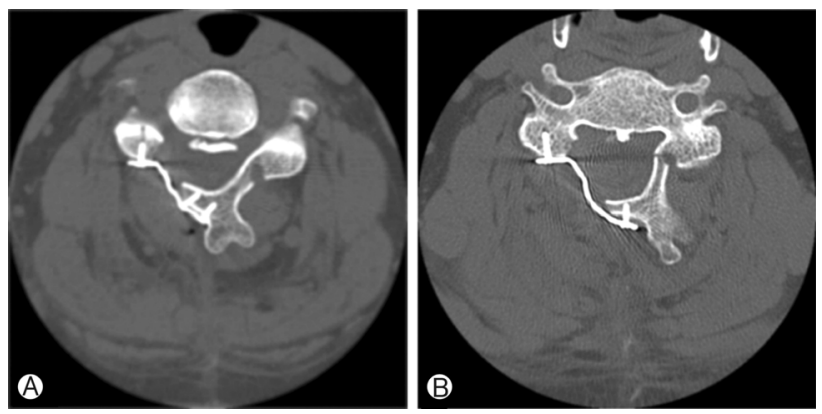

Fig. 1. CT scans taken on postoperative 2 days. (A) Deformed. The ventral cortex remained intact. (B) Fractured. The ventral cortex was broken.
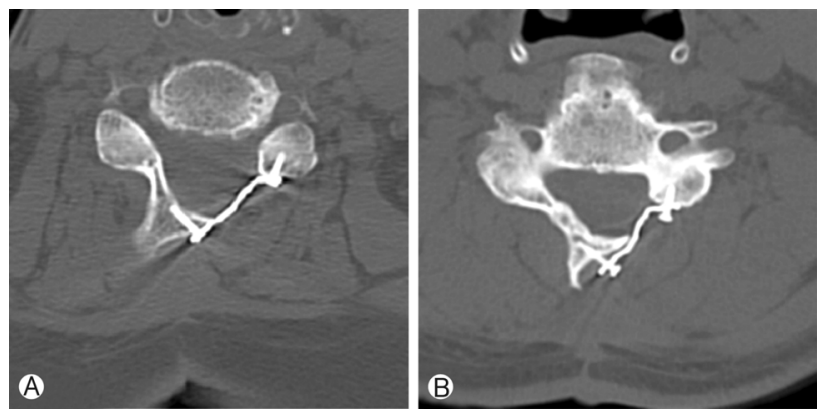

Fig. 2. (A) Cortically remodeled hinge. (B) The ventral and dorsal cortices are bridged by cancellous bone.

spine were taken. The angles were measured by a line parallel to the inferior aspect of the $\mathrm{C} 2$ vertebral body and a line parallel to that of the C7 vertebral body. The cervical lordotic angle was evaluated by these angles of neutral view. Range of motion (ROM) of the cervical spine was assessed by measuring the difference in these angles at flexion and extension ${ }^{4)}$. ROM change rates were calculated in the following manner: $(\mathrm{ROM}$ change rate, $\%)=($ postoperative $\mathrm{ROM}$ - preoperative $\mathrm{ROM}) /($ preoperative $\mathrm{ROM}) \times 100$. Postoperative outcomes were evaluated 12 months after the surgery.

Cervical CT scans were obtained at 2 days, 3 months, 6 months, 12 months, and 24 months post-operation (Table 1). After evaluating the initial status of the hinges using 2-daypostoperative CT scans, the hinges were classified into two groups: 'Deformed' and 'Fractured'. 'Deformed' indicated that the ventral cortex remained intact and demonstrated a favorable greenstick deformation. 'Fractured' indicated that the ventral cortex was broken and demonstrated unfavorable greenstick deformation (Fig. 1). The overall healing status of the hinges was determined by evaluating the status of each cortex (dorsal and ventral) according to the matrix presented in Table $3^{6}$. A hinge was defined as being 'healed' only if both the dorsal and ventral cortices were bridged by bone (Fig. 2). If the ventral cortex had cortical bridging, but the
Table 3. Definitions of hinge healing status*

\begin{tabular}{cccc}
\hline \hline & & \multicolumn{2}{c}{ Ventral cortex } \\
& & Bridged & Not bridged \\
\hline \multirow{2}{*}{ Dorsal cortex } & Bridged & Healed & Not healed \\
& Not bridged & Not healed & Not healed \\
\hline
\end{tabular}

*Both the ventral and dorsal cortices must be bridged with bone to be considered healed

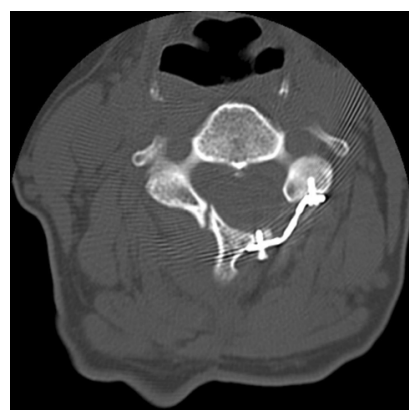

Fig. 3. Hinge nonunion with no bone bridging either dorsal or ventral cortices of the hinge. dorsal cortex had neither cortical nor cancellous bridging, the hinge was defined as 'not healed' (Fig. 3).

The lordotic angles and ROMs were performed twice, with a week interval in between the two measurements, by two of the authors, and the mean data was evaluated. The status of each hinge was determined by a consensus of two or more of the three reviewers. All measurements were made using a picture-archiving communications system (Maroview, version 5.4; Marotech, Inc., Seoul, Korea).

Twenty-three 2-day-postoperative CT scans were sorted by their clinical and radiographic outcomes into two groups based on the existence of 'fractured' hinges or lack thereof. At 12 months post-operation, new CT scans were once again sorted, using the same methods, into two groups according to the existence or nonexistence of 'not healed' hinges. The healing status of each hinge was measured at every evaluation.

\section{Statistical Analysis}

Statistical analysis was performed using SPSS statistical software package 18.0 for Windows (SPSS Inc, Chicago, USA). The Mann-Whitney U-test and Fisher's exact test were used to analyze differences and evaluate statistical significance, which was set at the $p=0.05$ level.

\section{RESULTS}

\section{1. 'Deformed' versus 'Fractured' Hinges}

There were 7 patients who did not have any 'fractured' 
Table 4. Clinical and radiographic outcome parameters of the patients to be available CT scans at postoperative 2 days

\begin{tabular}{|c|c|c|c|}
\hline & $\begin{array}{c}\text { No } \\
\text { fractured } \\
\text { hinge }\end{array}$ & $\begin{array}{l}\text { Fractured } \\
\text { hinge }\end{array}$ & p-value \\
\hline Number of patients & 7 & 16 & \\
\hline Age & $61.1 \pm 16$ & $62.4 \pm 8.8$ & 1.000 \\
\hline $\operatorname{Sex}(M / F)$ & $3 / 4$ & $13 / 3$ & 0.137 \\
\hline OPLL/CSM & $5 / 2$ & 9/7 & 0.657 \\
\hline Preop VASn & $6.0 \pm 1.7$ & $4.3 \pm 2.6$ & 0.154 \\
\hline Postop VASn & $2.6 \pm 1.1$ & $1.4 \pm 1.4$ & 0.047 \\
\hline Preop VASa & $5.4 \pm 1.3$ & $5.1 \pm 2.1$ & 0.720 \\
\hline Postop VASa & $1.4 \pm 1.8$ & $1.6 \pm 1.6$ & 0.820 \\
\hline Preop NDI & $54.6 \pm 15.8$ & $34.7 \pm 24.6$ & 0.065 \\
\hline Postop NDI & $21.1 \pm 12.6$ & $16.3 \pm 11.6$ & 0.341 \\
\hline Preop JOA & $10.0 \pm 3.3$ & $12.7 \pm 2.4$ & 0.076 \\
\hline Postop JOA & $14.7 \pm 2.1$ & $15.9 \pm 1.1$ & 0.249 \\
\hline JOA score achieve & $4.7 \pm 3.1$ & $3.1 \pm 2.1$ & 0.175 \\
\hline JOA score recovery rate (\%) & $77.9 \pm 24.4$ & $72.8 \pm 27.8$ & 0.769 \\
\hline Preop lordotic angle $\left({ }^{\circ}\right)$ & $29.5 \pm 15.9$ & $11.0 \pm 8.4$ & 0.012 \\
\hline Postop lordotic angle $\left(^{\circ}\right)$ & $24.9 \pm 12.0$ & $7.2 \pm 11.6$ & 0.008 \\
\hline Lordotic angle change $\left({ }^{\circ}\right)$ & $4.5 \pm 6.7$ & $3.9 \pm 8.8$ & 0.974 \\
\hline Preop $\operatorname{ROM}\left({ }^{\circ}\right)$ & $46.0 \pm 2.5$ & $34.9 \pm 14.1$ & 0.012 \\
\hline Postop ROM( $\left.{ }^{\circ}\right)$ & $27.4 \pm 13.8$ & $16.0 \pm 11.1$ & 0.065 \\
\hline $\mathrm{ROM}$ change $\left({ }^{\circ}\right)$ & $18.6 \pm 12.8$ & $18.8 \pm 11.9$ & 0.820 \\
\hline $\mathrm{ROM}$ change rate (\%) & $41.0 \pm 28.9$ & $55.9 \pm 25.8$ & 0.308 \\
\hline
\end{tabular}

Note: Values are mean \pm SD.

OPLL, Ossification of the posterior longitudinal ligament; CSM, cervical spondylotic myelopathy; Preop, preoperative; VASn, visual analog system of neck pain; Postop, postoperative; VASa, visual analog system of arm pain; NDI, neck disability index; JOA, Japanese Orthopaedic Association; ROM, range of motion; SD, standard deviation.

hinges, and 16 patients who had one or more 'fractured' hinges. Seven patients had only one 'fractured' hinge, 4 patients had two, 3 patients had three, and 2 patients had four. Table 4 shows preoperative and postoperative clinical and radiographic parameters for both groups. Several factors were statistically different, but most of the parameters were similar. Postoperative VASn in the 'deformed' group was higher than that of the 'fractured' group $(p=0.047)$, but NDI scores did not have any statistical variance. Preoperative and postoperative lordotic angles in the 'fractured' group were lower than those in the 'deformed' group $(p=0.012,0.008)$. The degrees of angle change were similar $(\mathrm{p}=0.974)$.

\section{2. 'Healed' versus 'Not Healed' Hinges at 12 Months Postoperative}

In 14 patients, all hinges had healed by 12 months post-

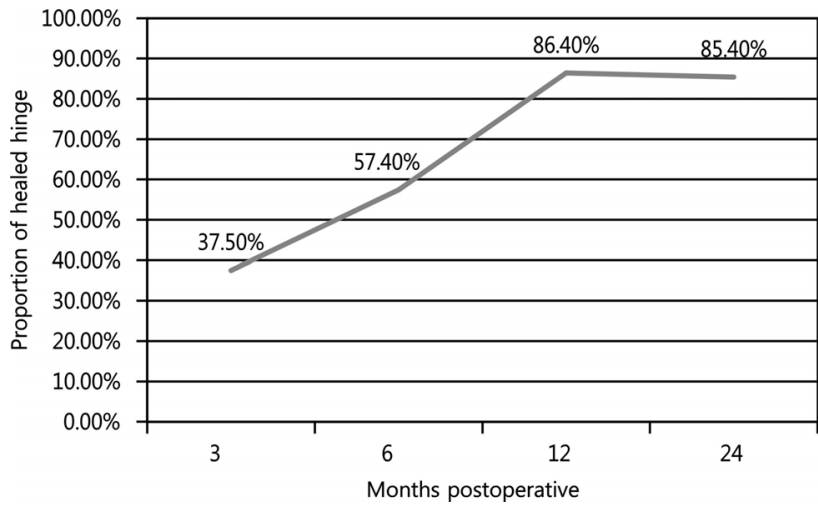

Fig. 4. The overall proportion of healed hinges at each time point.

Table 5. Clinical and radiographic outcome parameters of the patients to be available CT scans at postoperative 12 months.

\begin{tabular}{lccc}
\hline \hline & Healed & Not healed & p-value \\
\hline Number of patients & 14 & 7 & \\
Age & $64.7 \pm 11.0$ & $59.3 \pm 12.3$ & 0.443 \\
Sex (M/F) & $6 / 8$ & $4 / 3$ & 0.659 \\
OPLL/CSM & $6 / 8$ & $4 / 3$ & 0.659 \\
Preop VASn & $4.1 \pm 2.7$ & $4.0 \pm 2.4$ & 1.000 \\
Postop VASn & $1.4 \pm 0.8$ & $2.0 \pm 0.8$ & 0.224 \\
Preop VASa & $5.5 \pm 1.8$ & $4.7 \pm 2.4$ & 0.488 \\
Postop VASa & $1.4 \pm 1.4$ & $2.1 \pm 2.1$ & 0.535 \\
Preop NDI & $35.8 \pm 23.5$ & $36.9 \pm 24.5$ & 0.971 \\
Postop NDI & $16.0 \pm 10.0$ & $15.1 \pm 8.0$ & 0.689 \\
Preop JOA & $12.3 \pm 2.6$ & $13.0 \pm 0.6$ & 0.535 \\
Postop JOA & $15.9 \pm 0.9$ & $15.6 \pm 1.3$ & 0.689 \\
JOA score achieve & $3.6 \pm 2.4$ & $2.6 \pm 1.4$ & 0.585 \\
JOA score recovery rate $(\%)$ & $74.3 \pm 20.6$ & $63.9 \pm 31.9$ & 0.585 \\
Preop lordotic angle $\left({ }^{\circ}\right)$ & $13.9 \pm 12.8$ & $6.7 \pm 10.3$ & 0.287 \\
Postop lordotic angle $\left({ }^{\circ}\right)$ & $8.4 \pm 16.2$ & $8.0 \pm 13.3$ & 0.689 \\
Lordotic angle change $\left({ }^{\circ}\right)$ & $1.5 \pm 11.6$ & $-1.24 \pm 4.3$ & 0.094 \\
Preop ROM $\left(^{\circ}\right.$ ) & $39.5 \pm 12.4$ & $36.4 \pm 7.5$ & 0.856 \\
Postop ROM $\left({ }^{\circ}\right)$ & $27.2 \pm 15.1$ & $23.6 \pm 9.4$ & 0.743 \\
ROM change $\left({ }^{\circ}\right)$ & $12.5 \pm 10.3$ & $12.8 \pm 9.6$ & 0.913 \\
ROM change rate $(\%)$ & $33.7 \pm 25.9$ & $34.2 \pm 21.1$ & 0.971 \\
\hline Note: Valus are mean & & &
\end{tabular}

Note: Values are mean \pm SD.

OPLL, Ossification of the posterior longitudinal ligament; CSM, cenvical spondylotic myelopathy; Preop, preoperative; VASn, visual analog system of neck pain; Postop, postoperative; VASa, visual analog system of arm pain; NDI, neck disability index; JOA, Japanese Orthopaedic Association; ROM, range of motion; SD, standard deviation.

operation. The other 7 patients had 'not healed' hinges: 3 patients had one, and 4 patients had two. Preoperative and postoperative clinicoradiographic parameters for both groups are summarized in Table 5. There was no significant difference between the two groups. 


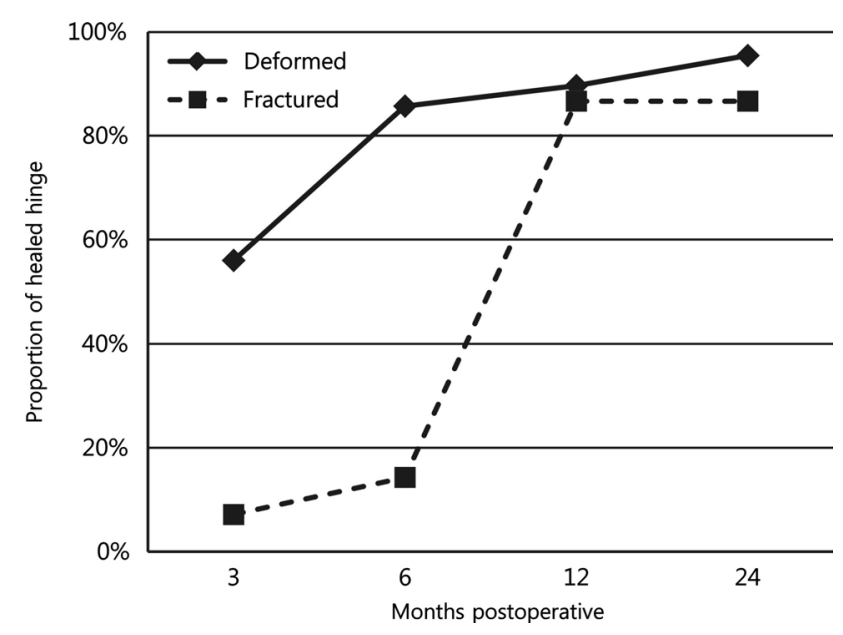

Fig. 5. The healing rate of 'Deformed' and 'Fractured' hinges identified at postoperative 2 days CT scan. Healing rates of hinges were similar after 1 year.

Table 6. Univariate comparison between 'fractured' group and 'deformed' group

\begin{tabular}{lccc}
\hline \hline & $\begin{array}{c}\text { Fractured } \\
(\mathrm{n}=33)\end{array}$ & $\begin{array}{c}\text { Deformed } \\
(\mathrm{n}=57)\end{array}$ & p-value \\
\hline Age (years) & $61.88 \pm 7.33$ & $62.7 \pm 12.56$ & 0.732 \\
Level & & & 0.692 \\
C3 & $5(15.2 \%)$ & $14(24.6 \%)$ & \\
C4 & $9(27.3 \%)$ & $1424.6 \%)$ & \\
C5 & $8(24.2 \%)$ & $15(26.3 \%)$ & \\
C6 & $8(24.2 \%)$ & $12(21.1 \%)$ & \\
C7 & $3(9.1 \%)$ & $2(3.5 \%)$ & \\
Gender (Male) & $19(57.7 \%)$ & $33(57.8 \%)$ & 0.743 \\
Smoking & $1(3.0 \%)$ & $8(14.0 \%)$ & 0.147 \\
BMD (T-score) & $0.6 \pm 1.72$ & $-0.05 \pm 1.96$ & 0.196 \\
Thickness of lamina (mm) & $4.4 \pm 1.15$ & $4.07 \pm 1.02$ & 0.177 \\
\hline
\end{tabular}

Note: Values are mean \pm SD.

$\mathrm{BMD}$, bone mineral density; SD, standard deviation.

\section{The Hinge Status According to Time}

The numbers of available hinges were $64,47,81$ and 41 at $3,6,12$, and 24 months respectively.

At 3, 6, 12, and 24 months 37.5, 57.4, 86.4\%, and 85.4\% had healed, respectively (Fig. 4). The healing rate of each 'deformed' and 'fractured' hinge was calculated. At 3 months, $56 \%$ of the 'deformed' hinges were healed, but only $7.1 \%$ of the 'fractured' hinges were healed; at 6 months, $85.7 \%$ and $14.3 \%$; at 12 months, $89.7 \%$ and $86.7 \%$; at 24 months, $95.5 \%$ and $86.7 \%$ respectively (Fig. 5). At 3 months, 56\% of the 'deformed' hinges were healed, but only $7.1 \%$ of the 'fractured' hinges were healed; at 6 months, $85.7 \%$ and 14.3\%;
Table 7. Univariate comparison between 'not healed' group and 'healed' group

\begin{tabular}{llll}
\hline \hline & $\begin{array}{c}\text { Not healed } \\
(\mathrm{n}=10)\end{array}$ & \multicolumn{1}{c}{$\begin{array}{c}\text { Healed } \\
(\mathrm{n}=71)\end{array}$} & p-value \\
\hline $\begin{array}{llll}\text { Age (years) } \\
\text { Level }\end{array}$ & $58.3 \pm 11.13$ & $64.21 \pm 10.88$ & 0.142 \\
C3 & $1(10 \%)$ & $15(21.13 \%)$ & 0.332 \\
C4 & $3(30 \%)$ & $18(25.35 \%)$ & \\
C5 & $5(50 \%)$ & $16(22.54 \%)$ & \\
C6 & $1(10 \%)$ & $19(27.14 \%)$ & \\
C7 & $0(0 \%)$ & $3(4.23 \%)$ & \\
Gender (Male) & $6(60 \%)$ & $32(45.71 \%)$ & 0.503 \\
Smoking & $0(0 \%)$ & $0(0 \%)$ & \\
BMD (T-score) & $1.92 \pm 1.76$ & $0.01 \pm 1.74$ & 0.027 \\
Thickness of lamina (mm) & $3.1 \pm 0.55$ & $3.85 \pm 1.08$ & 0.036 \\
\hline
\end{tabular}

Note: Values are mean \pm SD.

$\mathrm{BMD}$, bone mineral density; SD, standard deviation.

at 12 months, $89.7 \%$ and $86.7 \%$; at 24 months, $95.5 \%$ and 86.7\% (Fig. 5).

\section{Risk Factors of Hinge Status}

To evaluate the risk factors associated with hinge fracture and healing, the following variables were analyzed: age, gender, level of laminoplasty, smoking history, bone mineral density (BMD), and lamina thickness. The 'not healed' hinge group had low lamina thickness (Table 7). However, there was no statistical significance between the 'fractured' hinge group and the 'deformed' hinge group (Table 6).

\section{DISCUSSION}

In the present study, it was found that hinge fractures or the status of hinge healing may not affect clinical and radiographic outcomes of open-door laminoplasty. Postoperative VASa, postoperative JOA scores, RR of JOA score, and the achieved JOA score were not statistically different between the 'deformed' and 'fractured' groups. VASn scores in the 'deformed' group were higher than those of the 'fractured' group $(p=0.047)$. However, NDI scores, another parameter associated with neck pain, did not have a statistical difference. Therefore, it is difficult to conclude that patients without 'fractured' hinges have more severe postoperative neck pain. Postoperative ROM and ROM change of the 'fractured' group were not statistically different from those of the 'deformed' group. Postoperative lordotic angles in the 'fractured' group were lower than those of the 'deformed' group; however, the 
degrees of angle change were not significantly different. These lower lordotic angles may have been due to lower preoperative lordotic angles. Therefore, there was no statistical difference between the 'healed' and 'not healed' group regarding the clinical and radiographic outcomes.

There was no relationship between neck pain at 1 year post-operation for 'fractured' and 'not healed' hinges in our series. However, several papers reported that HFs may be a source of postoperative pain. Hirabayashi, et al. warned that HFs could cause transient paresis as well as pain ${ }^{3)}$. Satomi, et al. described how displacement of osteotomized laminae may lead to severe neck pain ${ }^{7}$. Park, et al. reported that the presence of three or more 'unfavorable' hinges was associated with increased postoperative neck pain ${ }^{5)}$. However, the criteria for 'unfavorable' hinge status are different from 'not healed' criteria, and there are no three or more 'not healed' hinges in our series. As a consequence of this discrepancy, further studies are needed.

As for the frequency of hinge fractures, the location of the hinge, the width of the hinge, and the presence of traumatic handling have been proposed to be important variables ${ }^{3,5}$. Age, BMD, smoking history, and gender, however, were not hinge-fracture risk factors in this study. Nonetheless, hinge healing was associated with the lamina's thickness. To avoid hinge breakdown, the open side must be detached before drilling; the hinge side and hinge stability must be frequently checked while elevating the spinous process ${ }^{3)}$. When thin laminae are identified in preoperative image studies, a more circumspect stratagem is needed during the elevation process.

The actual incidence of HFs and the healing rate of hinges had rarely been reported before this study. Park, et al. reported that $\sim 10 \%$ of hinges had been broken as early as 1 week postoperative. 5 Rhee, et al. found hinge healing rates of $55 \%$ at 3 months, $77 \%$ at 6 months, and $93 \%$ at 12 months ${ }^{6}$. The proportion of hinge fractures at 2 days post-operation was slightly high (36.7\%), and overall hinge healing occurred in $37.5 \%$ of hinges at 3 months, $57.4 \%$ at 6 months, $86.4 \%$ at 12 months, and $85.4 \%$ at 24 months in this study.

The healing rate of 'fractured' hinges was lower than the healing rate of 'deformed' hinges. In order to heal hinges, some authors have used bone grafting on hinges ${ }^{11)}$. Bone graf ting on 'fractured' hinges may help to increase the healing rate; however, Rhee, et al. reported that the hinge healing rate was high in cervical open door laminoplasty with plates, so plate-only laminoplasty could avoid the added cost and operative time associated with the use of bone grafting ${ }^{6}$. In this study, the healing rate of 'fractured' hinges was similar to that of 'deformed' hinges at 12 months, and there was no difference in clinical and radiographic outcomes between the 'fractured' and the 'deformed' groups. For this reason, addi- tional bone grafting for 'fractured' hinges may not be necessary.

This study has several limitations. First, this study is retrospective. Some clinical data, such as shoulder pain or serial changes in neck pain, were not precisely recorded. Another limitation is the lack of published criteria for determining hinge status. Finally, our small population size and short-term follow-up period preclude more meaningful statistical data. Therefore, a longer-term study that encompasses a larger population needs to confirm these results.

\section{CONCLUSION}

Cervical open door laminoplasty is safe and provides stable reconstruction of the laminar expansion. In radiographs, the difference between hinges that had healed and hinges that had not healed was statistically negligible. The hinge status may not influence the clinical and radiographic outcomes of cervical open door laminoplasty. However, fractured hinges delay healing and decrease healing rate, and many non-healed hinges may cause postoperative neck pain. Therefore, the process of making hinges requires a fastidious procedure. Even if hinge fractures are identified during the surgery, bone grafting for hinge healing may not be necessary.

\section{REFERENCES}

1. Goto T, Ohata K, Takami T, Nishikawa M, Tsuyuguchi N, Morino $\mathrm{M}$, et al: Hydroxyapatite laminar spacers and titanium miniplates in cervical laminoplasty. Journal of Neurosurgery 97: 323-329, 2002

2. Hirabayashi K, Miyakawa J, Satomi K, Maruyama T, Wakano $\mathrm{K}$ : Operative results and postoperative progression of ossification among patients with ossification of cervical posterior longitudinal ligament. Spine 6:354-364, 1981

3. Hirabayashi K, Satomi K: Operative procedure and results of expansive open-door laminoplasty. Spine 13:870-876, 1988

4. Kang SH, Rhim SC, Roh SW, Jeon SR, Baek HC: Postlaminoplasty cervical range of motion: early results. Journal of Neurosurgery Spine 6:386-390, 2007

5. Park YK, Lee DY, Hur JW, Moon HJ: Delayed hinge fracture after plate-augmented, cervical open-door laminoplasty and its clinical significance. The Spine Journal: Official Journal of the North American Spine Society, 2013

6. Rhee JM, Register B, Hamasaki T, Franklin B: Plate-only open door laminoplasty maintains stable spinal canal expansion with high rates of hinge union and no plate failures. Spine 36:9-14, 2011

7. Satomi K, Nishu Y, Kohno T, Hirabayashi K: Long-term follow-up studies of open-door expansive laminoplasty for cervical stenotic myelopathy. Spine 19:507-510, 1994

8. Seichi A, Takeshita K, Ohishi I, Kawaguchi H, Akune T, Anamizu $\mathrm{Y}$, et al: Long-term results of double-door laminoplasty for cer- 
vical stenotic myelopathy. Spine 26:479-487, 2001

9. Tanaka N, Nakanishi K, Fujimoto Y, Sasaki H, Kamei N, Hamasaki $\mathrm{T}$, et al: Expansive laminoplasty for cervical myelopathy with interconnected porous calcium hydroxyapatite ceramic spacers: comparison with autogenous bone spacers. Journal of Spinal Disorders \& Techniques 21:547-552, 2008

10. Vernon H, Mior S: The Neck Disability Index: a study of reli- ability and validity. Journal of Manipulative and Physiological Therapeutics 14:409-415, 1991

11. Xia Y, Xia Y, Shen Q, Li H, Xu T: Influence of hinge position on the effectiveness of expansive open-door laminoplasty for cervical spondylotic myelopathy. Journal of Spinal Disorders \& Techniques 24:514-520, 2011 